\title{
Childhood Nodular Lymphocyte Predominant Hodgkin Lymphoma
}

National Cancer Institute

\section{Source}

National Cancer Institute. Childhood Nodular Lymphocyte Predominant Hodgkin

Lymphoma. NCl Thesaurus. Code C8060.

A nodular lymphocyte predominant Hodgkin lymphoma occurring in children. 